International Journal on Intelligent Electronic Systems, Vol. 6 No. 1 January 2012

\title{
PHOTOELECTROCHEMICAL BEHAVIOUR OF PULSE PLATED SNSE FILMS
}

\author{
Ananthi $\mathrm{K}^{1}{ }^{1}$, Dhanapandian $\mathrm{S}^{2}$, Muthukumarasamy $\mathrm{N}^{3}$, Thilagavathy $\mathrm{K}^{4}$, Murali $\mathrm{K} . \mathrm{R}^{5}$ \\ ${ }^{1,3,4}$ Dept of Physics, CIT, Coimbatore, India \\ ${ }^{2}$ Dept of Physics, Annamalai University, Chidambaram, India \\ ${ }^{5}$ ECMS Division, CSIR-CECRI, Karaikudi, India \\ Email: ${ }^{1}$ kananthiphycit@gmail.com, ${ }^{2}$ dhanahockey@yahoo.co.in, ${ }^{5}$ muraliramkrish@gmail.com
}

\section{ABSTRACT}

The IV-VI compounds are technologically important in view of their applications in detectors and IR lasers. In this work, the pulse - plating technique has been employed for the deposition of SnSe films at different duty cycles. The films were polycrystalline with peaks corresponding to the orthorhombic structure. The grain size varied in the range of $40-$ $80 \mathrm{~nm}$ with increase of duty cycle. The surface roughness of the films varied from 0.5 to $1.5 \mathrm{~nm}$. The band gap increased from $1.26-1.50 \mathrm{eV}$ with duty cycle. Photoelectrochemical cell studies indicated $4.93 \%$ efficiency at $60 \mathrm{~mW} \mathrm{~cm}^{-2}$ illumination after photoetching.

Keywords: IV - VI,SnSe, thin films, semiconductor, electronic material.

\section{INTRODUCTION}

The electronic and optical properties of IV - VI compounds, make them attractive for their use in diverse technological applications such as cut-off devices and photovoltaic cells, and in the manufacture of infrared lasers $[1,2]$ and detectors. They have also been studied for the evaluation of nanostructures etching [3]. In particular, SnS and SnSe have been used as shells for $\mathrm{PbSe}$ and $\mathrm{PbS}$ quantum dots, for the development of infrared-based devices. SnSe thin films have been deposited by different methods like vacuum evaporation [4], flash evaporation [5], hot wall epitaxy [6], reactive evaporation [7], electrodeposition [8], laser ablation [9], chemical bath deposition (CBD) [10] and electrochemical atomic layer epitaxy (ECALE) [11] to study various physical properties. In this investigation, SnSe films were deposited for the first time using the pulse electrodeposition.

\section{EXPERIMENTAL METHODS}

SnSe films were deposited by the pulse electrodepsoition technique at room temperature from a bath containing Analar grade $50 \mathrm{mM}$ tin chloride $\left(\mathrm{SnCl}_{4}\right)$ and $5 \mathrm{mM} \mathrm{SeO}_{2}$. The deposition potential was maintained as $-0.9 \mathrm{~V}$ (SCE). Tin oxide coated glass substrates $(5.0 \mathrm{ohms} / \mathrm{sq})$ was used as the substrate. The duty cycle was varied in the range of $6-50 \%$. Thickness of the films measured by surface profilometer increased from $500 \mathrm{~nm}$ to $1000 \mathrm{~nm}$ as the duty cycle increased from $6 \%$ to $50 \%$. Structural, optical, electrical and photoelectrochemical (PEC) properties of the films were studied. For PEC studies $1 \mathrm{M}$ polysulphide was used as the redox electrolyte.

\section{RESULTS AND DISCUSSION}

The XRD patterns of SnSe thin films (Fig. 1), deposited at different duty cycles indicate the peaks around $2 \theta=30^{\circ}$ corresponding to (111) diffraction

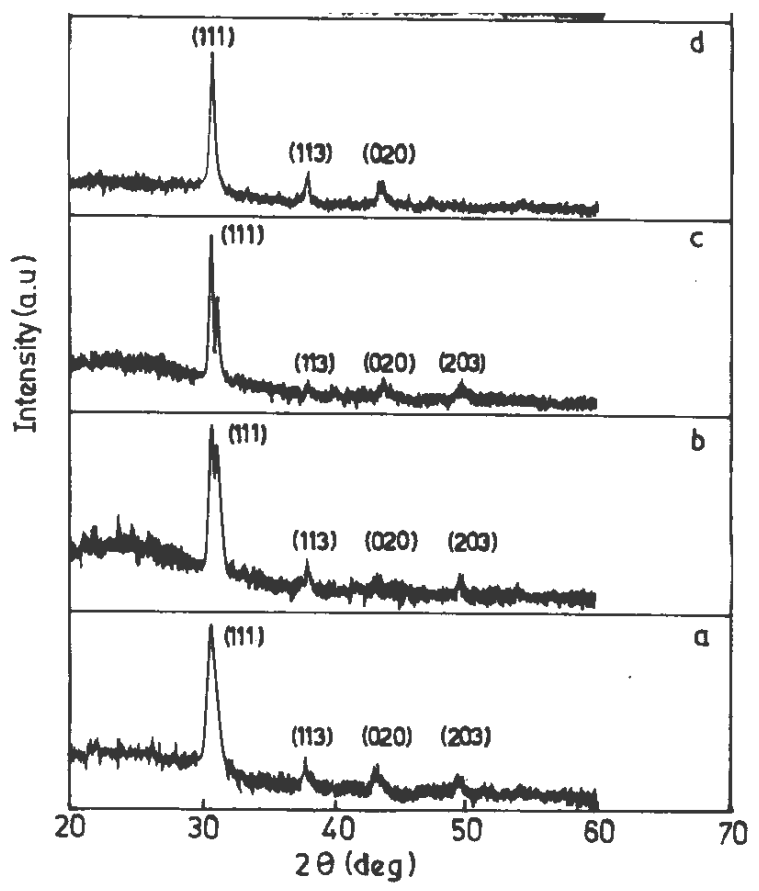

Fig. 1. XRD pattern of SnSe films deposited at different duty cycles

(a) $9 \%$ (b) $15 \%$ (c) $33 \%$ (d) $50 \%$ 
plane, along with three other very weak diffraction peaks viz. (113), (020), (203), which confirms the polycrystalline nature of the film. A similar preferred orientation of grains along the (111) plane in SnSe film was observed in the evaporated SnSe thin films. The analysis of the diffraction patterns also suggests that the SnSe thin-film has orthorhombic structure with lattice parameters $a=b=0.429 \mathrm{~nm}$ and $c=0.523 \mathrm{~nm}$. The XRD data of the films matches well with JCPDS data card no. 32-1392. Furthermore, it is observed that as duty cycle increases the intensity of the diffraction peaks increases. This could be linked with the grain-growth with increase in duty cycle. The crystallite size was estimated by using Scherrer's equation and it was found to increase from $37 \mathrm{~nm}$ to $78 \mathrm{~nm}$ with increase of duty cycle.

Energy dispersive X-ray spectra of SnSe thin films revealed that the $S n$ and $S e$ contents depend critically on the duty cycle. It is seen that the SnSe thin films formed at duty cycles less than 50\% contained a slight excess of selenium. The films deposited at $50 \%$ duty cycle was nearly stoichiometric and the calculated atomic percentages (at\%) of tin and selenium are 50.19 and 49.81 , respectively.

Strain $(\varepsilon)$ and grain size (D) are calculated using the relation

$$
\beta \cos \theta=\lambda / D-\varepsilon \sin \theta
$$

where; $\lambda$ is the wavelength of the radiation used $(0.15418 \mathrm{~nm}), \beta$ the full width at half maximum, and $\theta$ the angle of diffraction. A graph is drawn between $\beta$ cose and $\sin \theta$ for various $\theta$ values taken from the peaks of the corresponding plane (111). From the

Table 1. Microstructural parameters of SnSe films deposited at different duty cycles

\begin{tabular}{|c|c|c|c|}
\hline $\begin{array}{l}\text { Duty cycle } \\
(\%)\left(10^{15}\right)\end{array}$ & $\begin{array}{c}\text { strain } \\
\left(\times 10^{-3}\right)\end{array}$ & $\begin{array}{c}\text { grain } \\
\text { size }(n m)\end{array}$ & $\begin{array}{c}\text { Dislocation } \\
\text { density } \\
\text { lines } / \mathrm{m}^{2}\end{array}$ \\
\hline 6 & 1.97 & 40 & 6.25 \\
\hline 9 & 1.56 & 52 & 2.69 \\
\hline 15 & 1.35 & 60 & 2.77 \\
\hline 33 & 1.14 & 71 & 1.98 \\
\hline 50 & 1.01 & 80 & 1.52 \\
\hline
\end{tabular}

intercept and slope of the straight line plots, the particle size (D) and strain $(\varepsilon)$ in the film are calculated. The dislocation density $(\delta)$ is determined from the relation

Transmission measurements were made in the wavelength range $750 \mathrm{~nm}$ to $2300 \mathrm{~nm}$. The spectra exhibited interference fringes (Fig. 2). Refractive index of the films was calculated by the envelope method. The value of refractive index at $780 \mathrm{~nm}$ was 2.1 , this value decreased to 1.95 with decrease of duty cycle. These values are in agreement with earlier reports. The bandgap was estimated from the transmission spectra and it varied from $1.26 \mathrm{eV}$ to $1.50 \mathrm{eV}$ with decrease of duty cycle. This is understandable, since the grain size decreases with decrease of duty cycle, hence, the bandgap value increases due to quantum size effects.

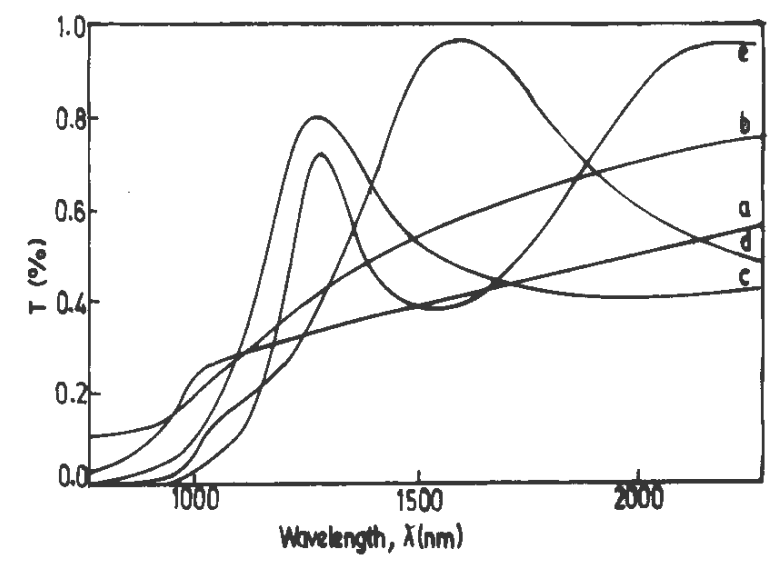

Fig. 2. Transmission spectra of SnSe films deposited at different duty cycles (a) $6 \%$ (b) $9 \%$ (c) $15 \%$ (d) $33 \%$ (e) $50 \%$

Photoelectrochemical cell studies were made using $1 \mathrm{M}$ polysulphide (1 MS, $1 \mathrm{M} \mathrm{Na}_{2} \mathrm{~S}, 1 \mathrm{M} \mathrm{NaOH}$ ) as the redox electrolyte. Graphite was used as the counter electrode. The films deposited at lower duty cycles exhibited very poor photo output after post annealing in Argon atmosphere. Films deposited at duty cycles greater than $15 \%$ exhibited photo output. For a film deposited at $50 \%$ duty cycle, an open circuit voltage of $0.55 \mathrm{~V}$ and a short circuit current density of $5.0 \mathrm{~mA} \mathrm{~cm}^{-2}$ at $60 \mathrm{~mW} \mathrm{~cm}^{-2}$ illumination (Fig. 3).

Ideality factor of 1.85 and reverse saturation current of $1.5 \times 10^{-7} \mathrm{~A} \mathrm{~cm}^{-2}$ were obtained from the variation of open circuit voltage and short circuit current with intensity of illumination. The effect of photoetching on the PEC performance was studied by shorting the 


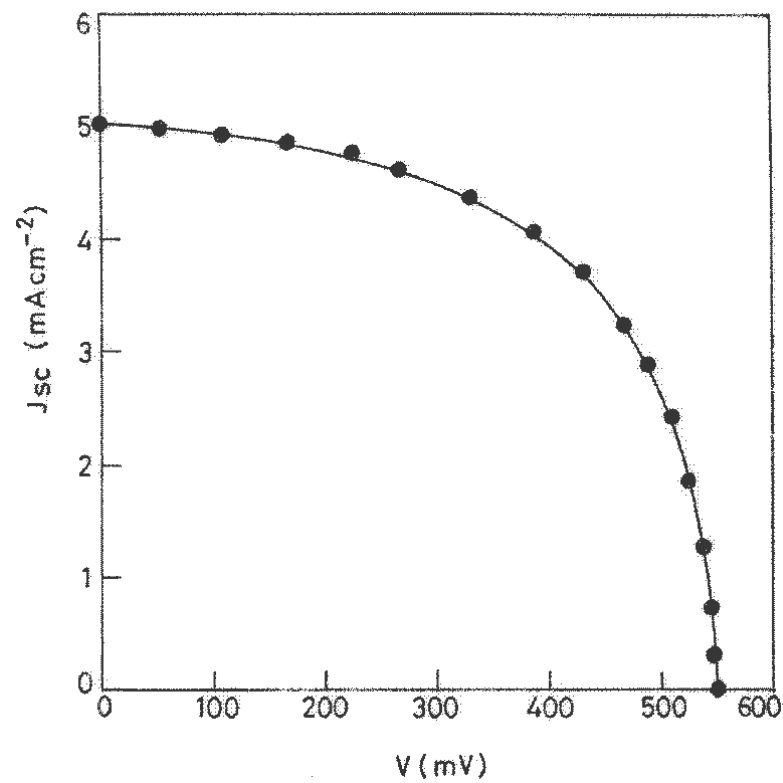

Fig. 3. Load characteristics of the photoelectrochemical cell made with SnSe film deposited at a duty cycle of $50 \%$

photoelectrode and the graphite counter electrode under an illumination of $80 \mathrm{mWcm}^{-2}$ in $1: 100 \mathrm{HCl}$ for different for different durations in the range $0-100 \mathrm{~s}$. Both the photocurrent and photovoltage are found to increase upto $80 \mathrm{~s}$ photoetch, beyond which they begin to decrease (Fig. 5). Photoetching leads to selective attack of surface defects not accessible to chemical etchants. It is observed that during photoetching the $\mathrm{V}_{\text {oc }}$ increased from $0.55 \mathrm{~V}$ to $0.65 \mathrm{~V}$ and $\mathrm{J}_{\mathrm{sc}}$ increased from $5.00 \mathrm{mAcm}^{-2}$ to $7.00 \mathrm{mAcm}^{-2}$. The decrease in photocurrent and photovoltage beyond $80 \mathrm{~s}$ photoetching can be attributed to increase in surface area due to prolonged photoetching. The power output characteristics after $80 \mathrm{~s}$ photoetching indicates a $V_{O C}$ of $0.65 \mathrm{~V}, \mathrm{~J}_{\mathrm{sc}}$ of $7.00 \mathrm{~mA} \mathrm{~cm}{ }^{-2}, \eta$ of 0.65 , of $4.93 \%$ for $60 \mathrm{mWcm}^{-2}$ illumination.

\section{CONCLUSIONS}

This study clearly illustrates that the pulse plating technique can be employed for the deposition of nanocrystalline SnSe films. Films with low resistivity in the range of 1.0 to $10 \mathrm{ohm} \mathrm{cm}$ can be deposited. Films with transmission around $80 \%$ can be prepared. Photoelectrodes exhibiting $4.93 \%$ efficiency after photoetching can be prepared

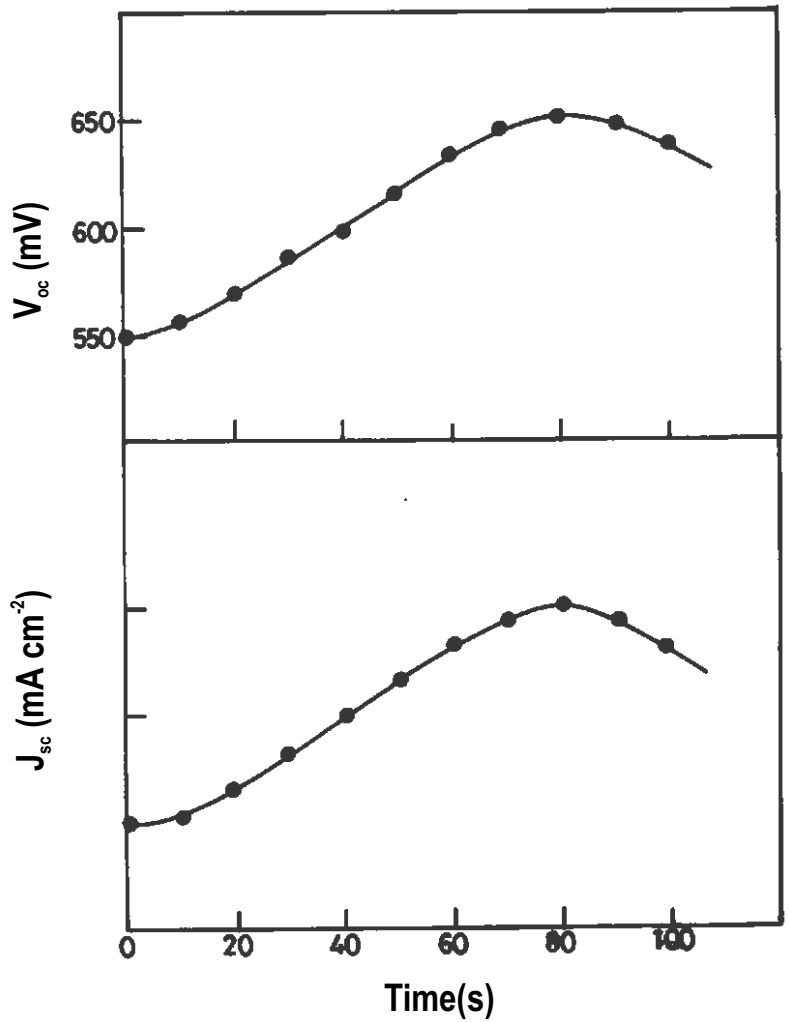

Fig. 4. Effect of Photoetching time on Voc and JSC

\section{REFERENCES}

[1] Shi Z, Xu G, McCann P.J, Fang X.M, Dai N, Felix C.L., Bewley W.W, Vurgaftman I, Meyer J.R., 2000, IV-VI compound mid infrared high-reflectivity mirrors and vertical surface emitting lasers grown by molecular beam epitaxy, Applied Physics Letters, 76,pp 3688 3692.

[2] Böberl. M, Heiss. W, Schwarzl. T, Wiesauer. K, Springholz. G, Midinfrared continuous wave photoluminescence of lead salt structures up to temperatures of $190 \mathrm{C}$, Applied Physics. Letters., 2008, 82, pp 4065 - 4070.

[3] Schwarzl. Th, Hei. W, Kocher-Oberlehner. G, Springholz. G, $\mathrm{CH}_{4} / \mathrm{H}_{2}$ plasma etching of IV-VI semiconductor nanostructures, Semiconductor Science and Techmology., 1999, 14, pp L11 - L13.

[4] Sharma. J, Singh. G, Thakur. A, Saini. G.S.S, Goyal. N, Tripathi S.K, Preparation and characterization of nanocrystalline SnSe films, Journal of Optoelectronic Advanced. Materials., 2005, 7, pp 2085 - 2094.

[5] Singh. J.P, Bedi. R.K, Electrical properties of flash evaporated in selenide films, Thin Solid Films 1991, 199, pp 9-12. 
[6] Singh. J.P, Transport and optical properties of hot wall grown tin selenide films, Journal of Materials. Science: Materials in Electron., 1991, 2, pp 105 - 108, 1991.

[7] John. K.J, Pradeep. B, Mathai. E, Tin selenide (SnSe) thin films prepared by reactive Evaporation., Journal of Materials Science., 1994, 29, pp 1581 - 1583.

[8] Zainal. Z, Nagalingam. S, Kassim. A, Hussein. M.Z, Yunus. W.M., Effects of Annealing on the properties of SnSe films, Solar Energy Material.Solar Cells, 2004, 81, pp 261- 268.

[9] Teghil. R, Santagata. A, Marotta. V, Orlando. S, Pizzella. G, Giardini-Guidoni. A, Mele. A,
Characterization of the plasma plume and of thin films epitaxially produced during laser ablaton of SnSe films, Applied Surface Science., 1995, 90, pp 505 - 514.

[10] Zainal. Z, Saravanan N, Anuar K, Hussein M.Z, Yunus. W.M.M, Chemical bath deposition of tin selenide thin films, Materials Scienec and Engineering. B., 2004, 107, pp 181 - 185.

[11] Qiao. Z, Shang W, Wang C, Fabrication of Sn-Se compounds on a gold electrode by electrochemical atomic layer epitaxy, Journal of Electroanalytical Chemistry., 2006, 576, pp 171 - 175. 